Published in final edited form as:

Cancer Causes Control. 2017 July ; 28(7): 667-675. doi:10.1007/s10552-017-0903-1.

\title{
Breast cancer and exposure to tobacco smoke during potential windows of susceptibility
}

\author{
Alexandra J. White ${ }^{1}$, Aimee A. D’Aloisio ${ }^{1,2}$, Hazel B. Nichols ${ }^{3}$, Lisa A. DeRoo ${ }^{4}$, and Dale P. \\ Sandler ${ }^{1}$ \\ ${ }^{1}$ Epidemiology Branch, National Institute of Environmental Health Sciences, NIH, Research \\ Triangle Park, NC, USA, 27709 \\ ${ }^{2}$ Social \& Scientific Systems, Inc., Durham, NC, USA, 27703 \\ ${ }^{3}$ Department of Epidemiology, University of North Carolina, Chapel Hill, NC, USA, 27599 \\ ${ }^{4}$ Department of Global Public Health \& Primary Care, University of Bergen, Bergen, Norway
}

\section{Abstract}

Purpose-An association between smoking and breast cancer is unresolved, although a higher risk from exposure during windows of susceptibility has been proposed. The objective of this prospective study was to evaluate the association between tobacco smoke and breast cancer with a focus on timing of exposure, especially during early life.

Methods-Sister Study participants ( $\mathrm{n}=50,884)$ ages 35-74 were enrolled from 2003-2009. Women in the United States and Puerto Rico were eligible if they were breast cancer-free but had a sister with breast cancer. Participants completed questionnaires on smoking and environmental tobacco smoke (ETS) exposure. Cox regression was used to estimate adjusted hazard ratios (HRs) and $95 \%$ confidence intervals (95\% CIs) for breast cancer risk

Results-During follow-up (mean=6.4 years), 1,843 invasive breast cancers were diagnosed. Neither active smoking nor adult ETS was associated with breast cancer risk. However, never smoking women exposed to ETS throughout their childhood had a 17\% higher risk of breast cancer (95\% CI: 1.00-1.36) relative to those with no exposure. In utero ETS exposure was also associated with breast cancer (HR=1.16, 95\% CI: 1.01-1.32) and the HR was most elevated for women born in earlier birth cohorts $(<1940, \mathrm{HR}=1.44,95 \%$ CI: 1.02-2.02; 1940-1949, HR=1.28, 95\% CI 1.01-1.62).

Conclusion-In utero ETS and ETS exposure during childhood and adolescence was associated with increased risk of breast cancer and varied by birth cohort.

\section{Keywords}

breast cancer; tobacco smoke; early life; environmental tobacco smoke

*Corresponding Author: Alexandra J. White, PhD, MSPH; Epidemiology Branch, National Institute of Environmental Health Sciences, NIH, Research Triangle Park, NC, 27709-2233 USA, Telephone: (919) 316-4797; Fax: (301) 480-3290; alexandra.white@nih.gov.

Conflicts of Interest. The authors have no conflicts of interest to declare. 


\section{Introduction}

Active smoking and environmental tobacco smoke (ETS) exposure can result in inhaling tobacco-related carcinogens relevant to breast cancer risk. Tobacco smoke contains several established carcinogenic compounds, including polycyclic aromatic hydrocarbons (PAHs), aromatic amines and $N$-nitrosamines $(1,2)$. Metabolites and chemicals from cigarette smoke have been shown to reach the breast, as both nicotine and cotinine have been measured in breast fluid (3). Smoking has also been associated with DNA adducts (3-5) and p53 mutation smoking signatures in breast tissue (6) which promote carcinogenesis. The 2014 Surgeon General's report stated that "the evidence is suggestive but not sufficient to infer a causal relationship" between breast cancer and active smoking or ETS exposure (7). Since the report was published there have been a number of cohort studies that have supported an association between tobacco smoke and breast cancer (8-15).

The Surgeon General's report on tobacco smoke identified a number of areas for improvement including more research on the effect of early age at smoking initiation or timing of ETS exposure on breast cancer risk, variation by tumor subtype and potential confounding by alcohol intake (7). Exposure to carcinogens during early life, a hypothesized biological window of susceptibility (16), may be especially relevant for breast cancer risk. Breast duct cells remain undifferentiated prior to first full-term pregnancy and thus, may be particularly susceptible to carcinogens; any genetic errors before first pregnancy would then be propagated by the extensive proliferation during pregnancy (17). Previous studies have found initiating smoking prior to first birth to be associated with breast cancer $(8-11,13,15$, $18)$.

In the study reported here, we aimed to evaluate the association between active smoking and ETS exposure on breast cancer risk with a focus on timing of exposure. We considered intensity and duration of tobacco smoke exposure, evaluated alcohol as a confounder and effect measure modifier and assessed variability by tumor estrogen receptor (ER) status.

\section{Materials and Methods}

\section{Study Population}

The National Institute of Environmental Health Sciences (NIEHS) Sister Study is a prospective cohort study of 50,884 women that was designed to investigate environmental and lifestyle risk factors for breast cancer. During 2003-2009, women throughout the U.S. and Puerto Rico were recruited using a multi-media campaign as well as a network of volunteers, breast cancer professionals, and advocates. Women, ages 35-74, were eligible for the study if they had no history of breast cancer themselves but they had a sister who had been diagnosed with breast cancer. At baseline, study participants completed an extensive computer assisted baseline telephone questionnaire on demographics, medical and family history, and lifestyle factors including active smoking history and lifetime exposure to environmental tobacco smoke. They also completed a mailed questionnaire on early life exposures that included questions on maternal and paternal smoking. 
This research was approved by the Institutional Review Boards of the NIEHS, NIH, and the Copernicus Group. Written informed consent was obtained from all participants. We included cases diagnosed with breast cancer as of July 1, 2014 (Sister Study Data Release 4.1).

Study participants update information on risk factors and report any changes in health status during annual health updates and biennial surveys. Response rates have been high at $94 \%$ over follow-up (19).

\section{Outcome Assessment}

Medical records are requested for women who report an incident breast cancer diagnosis to confirm diagnosis and obtain other relevant diagnostic and treatment information. Currently, medical records have been successfully obtained for greater than $80 \%$ of cases. Agreement between self-reported and medical record-abstracted data is high (20) thus, self-reported data were used when medical record data was unavailable. Tumor characteristics considered included whether the tumor was (1) stage 0, I, II-IV, (2) estrogen receptor-positive (ER+) or estrogen receptor-negative (ER-); and (3) ductal or lobular histologic type. Additionally, menopausal status at diagnosis (premenopausal or postmenopausal) was evaluated.

\section{Exposure and Covariate Assessment}

As part of the baseline questionnaire, women were asked about their own use of cigarettes and exposure to cigarette smoke from other people. Active smoking was defined as smoking at least one cigarette/day for at least six months. Participants reported the ages that they began and stopped smoking and the number of cigarettes per day/week/month that they smoked. This information was used to calculate year and decade-specific estimates of smoking duration and intensity, as well as lifetime summary estimates. Women were categorized by ever vs. never smoking status and ever smokers were further classified into current and past smokers (defined as not smoking within the previous 12 months). Age started smoking $(<15,15-19,20+$ years $)$, total pack-years $(<10,10-19,20-29,30+$ packyears), total years $(<10,10-19,20-29,30+$ years $)$, time since smoking in past smokers $(<10$, $10-24,25+$ years $)$ and usual cigarettes per day in current smokers $(<10,10-19,20+$ cigarettes/day) were considered relative to never smokers. We conducted a secondary analysis restricting the referent group, never smokers, to those also without ETS exposure during childhood or adulthood.

Limiting to parous women, smoking status relative to first full-term pregnancy was considered as pack-years of smoking $(<5,5-9,10+$ pack-years) completed before and after first full-term pregnancy ( $>37$ weeks gestation). We also considered pack-years by decade of young life $(<30$ years, 30-39, 40-49) in all women.

ETS exposure was evaluated for three time periods: (1) in utero, (2) childhood and adolescence (defined as exposures occurring from birth to 18 years of age) and (3) adult (>18 years of age). For both childhood and adult periods, women were determined to be ETS exposed if someone smoked $\geq 1$ cigarettes/day in their presence for a period of at least 6 months. Total years of ETS (none, 0-9, 10-19, 20-29, 30+), years of adult ETS (none, 0-9, $10-19,20+$ ) and years of childhood ETS (none, 0-9, 10-14, 15-17, 18) were characterized. 
To assess in utero exposure to ETS, women were asked whether their mother or anyone else in the household smoked while she was pregnant and whether their biological father smoked in the three months prior to conception. Response options (definitely yes, probably yes, probably no, definitely no) were collapsed into two categories (1) definitely or probably yes and (2) definitely or probably no. All ETS exposures were evaluated in never smoking women.

Covariates of interest, including demographics, reproductive history, lifetime alcohol intake (average drinks/year prior to baseline interview), use of postmenopausal hormones and oral contraceptives were obtained from the interview. Height and weight at baseline were measured in a home visit by a trained examiner and were used to calculate body mass index $\left(\mathrm{BMI}, \mathrm{kg} / \mathrm{m}^{2}\right)$.

\section{Statistical Analysis}

Multivariable Cox proportional hazards models were used to estimate hazard ratios (HR) and $95 \%$ confidence intervals (CI) for the association between active smoking and ETS exposure measures and breast cancer risk. Statistical models used age as the time scale and person-time was accrued from age at study enrollment. Follow-up extended until study participants had an invasive breast cancer diagnosis or were censored at the date of last follow-up or if diagnosed with in situ disease. Outcome subgroup analyses were performed evaluating stage (0, I, II-IV), invasive hormone receptor status (ER+, ER-), histologic type (ductal, lobular) and menopausal status at diagnosis (premenopausal, postmenopausal). For subgroup analyses, cases who did not have the outcome of interest (for example: ERtumors when estimating the association for ER+ tumors), were censored at time of diagnosis. Similarly, in analyses investigating associations with menopausal status at the time of breast cancer diagnosis as an outcome, women who became postmenopausal during the follow-up period were censored at the time of menopause with respect to the outcome of premenopausal breast cancer. Consequently, the person-time that accumulated after menopause contributed to postmenopausal person-time at risk. The proportional hazard assumption was visually assessed using log-log survival plots as well as with the inclusion of an interaction term with survival time in the regression model, using $a=0.05$ to test for deviations. There was no suggestion of time-variant associations.

Stratified models were used to assess average lifetime alcohol intake (defined in quartiles: s0.4, 20.5-61.2, 61.3-143.8, 143.9+ average drinks/year over the lifetime) and birth cohort $(<1940,1940-1949,1950-1960,1960+)$ as potential effect measure modifiers. We also considered whether there was an interaction between active smoking and ETS exposure with breast cancer risk. Confounders were identified using the prior literature and a directed acyclic graph.(21) Multivariable-adjusted models included the following confounders: age, race (non-Hispanic white, other), education ( shigh school or equivalent, some college, 4year degree or higher), age at menarche (continuous), age at first birth (nulliparous, <21, 21$<25,25-<29,29-<32, \geq 32$ years), parity (nulliparous or 1, 2-3, 4+), use of oral contraceptives (ever, never), postmenopausal hormone use (none, estrogen only, estrogen and progesterone combined or both estrogen and estrogen and progesterone combined), age at menopause (premenopausal, <40, 40-50, 51-55, 55+ years based on enrollment 
information), lifetime alcohol consumption and body mass index $(<18.5,18.5-24.9,25.0$ $29.9,30+\mathrm{kg} / \mathrm{m}^{2}$ ). For early life exposures, specifically childhood and in utero ETS, a separate adjustment set was used which included age, race and childhood socioeconomic variables including household composition (two parents, single parent, other) at age 13, family income (well off, middle income, low income, poor) and highest household education at age 13 (less than high school, high school or equivalent, some college, 4-year degree or higher). A sensitivity analysis was conducted with childhood and in utero ETS exposure included in the model as potential confounders for the association between adult ETS exposure and breast cancer risk. Tests of trend used chi-square tests of continuous variables.

Two-sided tests were used with a p value of 0.05 to evaluate statistical significance. All analyses were performed using SAS version 9.3 software (SAS Institute, Inc., Cary, NC).

\section{Results}

Study population characteristics are displayed in Table I. Past smokers were more often white and slightly older compared to current or never smokers. Never smokers were more likely to have completed a 4-year college degree relative to smokers. Current smokers had an earlier age at menopause and had the highest average intake of alcohol.

Little to no association was observed with current or past smoking status, early age at initiation of smoking or with increasing years and pack-years of smoking (Table II). After further adjustment for lifetime alcohol intake most estimates were attenuated towards the null. Results for duration and intensity of smoking for past (not shown) and current smokers were similar, as were results when those with any ETS exposure were removed from the referent group (Supplemental Table I). There was no interaction observed between smoking status (never, former, current) and lifetime average alcohol intake, although the strongest breast cancer effect was observed among former smoking heavier drinkers (HR 1.44, 95\% CI: 1.11-1.85) (Supplemental Table 2). In analyses adjusted for lifetime alcohol intake, there was a suggestive positive association between current smoking and invasive postmenopausal breast cancer (HR=1.15, 95\% CI: 0.91-1.44), but not premenopausal breast cancer (Supplemental Table 3).

When limited to parous women, 10+ pack-years of smoking prior to first pregnancy was associated with a suggestive elevated risk of breast cancer (HR=1.22, 95\% CI 0.94-1.59) (Figure I). The association with smoking 10+ pack-years before age 30 did not largely differ from that of smoking 10+ pack-years later in life.

No elevated risk was observed for overall ETS or total years of ETS in never smokers (Table III). Rather, an inverse association was observed with adult ETS and breast cancer incidence (HR $=0.86,95 \%$ CI $0.74-1.00)$. This association remained unchanged with the addition of childhood and in utero ETS included in the model (data not shown). In contrast, having any childhood or adolescent ETS was associated with a higher breast cancer risk $(\mathrm{HR}=1.12,95 \%$ CI: 0.98-1.29) after adjustment for early life SES factors, age and race. Being exposed to ETS throughout childhood and adolescence (18 years) was also associated with an elevated risk (HR=1.17, 95\% CI: 1.00-1.36) relative to those with no childhood ETS exposure ( $p$ for 
trend=0.04). Study participant's mother's household ETS exposure while pregnant was associated with a higher breast cancer risk of similar magnitude (HR=1.16, 95\% CI: $1.01-$ 1.32) as was paternal smoking in the three months prior to the mother's pregnancy (HR=1.11, 95\% CI: 0.97-1.28). There was evidence of variability in the association between household ETS and breast cancer risk by birth cohort ( $p$ for interaction $=0.04$ ) with elevated estimates observed for those who were born prior to 1940 (HR=1.44, 95\% CI: 1.02, 2.02) or between 1940-1949 (HR=1.28, 95\% CI: 1.28, 1.01-1.62) but did not persist in women born between 1950-1959 or after 1960 (Figure II).

The association of any ETS exposure and invasive breast cancer was limited to women who were postmenopausal at diagnosis (postmenopausal HR=1.14, 95\% CI 0.89-1.46, versus premenopausal HR=0.79, 95\% CI 0.58-1.46) (Supplemental Table IV). We did not observe evidence of an interaction between active smoking and ETS exposure (data not shown).

\section{Discussion}

In this prospective cohort study we found that early life exposure to ETS, defined by in utero or childhood tobacco smoke exposure, was modestly associated with the risk of invasive breast cancer. We found little evidence to support previously reported associations with active smoking.

Early life events, such as birth weight (22) and in utero exposure to diethylstilbestrol (23), have previously been found to be associated with later development of breast cancer. Maternal smoking during pregnancy may result in altered hormone levels and thus may impact the fetus (24). Administration of carcinogens to the adult animal during pregnancy can result in mammary tumors in the mature offspring (25). Previous case-control studies have largely suggested modest positive associations with measures of in utero ETS exposure from either maternal or paternal sources, although results have not been statistically significant (26-32). However, interpretation of these studies is complicated by the potential for recall bias and these findings do conflict with prospective studies which have demonstrated inverse associations between maternal smoking during pregnancy and breast cancer risk (33) and breast cancer mortality (34). In this prospective study, we found that household ETS exposure while in utero, but not maternal smoking during pregnancy, was positively associated with breast cancer incidence, consistent with the findings from prior case-control studies. These associations were stronger in women who were born prior to 1950, which was likely due to increased intensity of smoking during that time. Paternal smoking prior to pregnancy was also associated with an increased risk, although this exposure may at least in part also be conflated with the increase in risk observed for household ETS.

Exposure to ETS during childhood and adolescence was associated with an elevated risk of breast cancer, particularly with 18 years of ETS exposure. Previous studies on childhood ETS exposure and breast cancer risk overall are inconsistent (7). Lin et al., 2008 (35) and Luo et al., 2011 (36) both reported positive, but nonsignificant association with childhood ETS in prospective cohort studies. Lin et al., 2008 relied on an ever/never childhood ETS assessment in a Japanese cohort (35). In the Women's Health Initiative, Luo and colleagues 
did include duration of childhood ETS; results were positive for postmenopausal women, but not statistically significant (36). In contrast, other studies have found null associations (37, 38) despite incorporating duration (38). The positive findings for both in utero and childhood ETS reported here require replication in other study populations.

In order to indirectly validate the assessment of the early life exposures, approximately 1,000 participant's mothers were asked the same questions as their daughters. In a preliminary analysis, agreement for in utero ETS exposures was high (kappa $\geq 0.8$ for maternal and paternal smoking and kappa $=0.7$ for household ETS) but was lower for childhood ETS exposure (kappa=0.5) [A. D'Aloisio, personal communication]. The lower kappa levels for childhood ETS were driven by mothers reporting ETS exposure whereas daughters reported no childhood ETS. This suggests that our results underestimate the proportion of women exposed to ETS during childhood and thus, may be attenuating the observed association towards the null.

Smoking prior to first pregnancy was not strongly associated with breast cancer risk although the observed HR for women with 10+ years of smoking prior to first pregnancy, though not statistically significant, was consistent with results from a recent meta-analysis that found a $20 \%$ increased risk of breast cancer for initiating smoking prior to first pregnancy (8), when breast tissue may be most susceptible to genotoxic exposures (39). It is possible our study was underpowered to statistically test this association.

Overall, we found only limited evidence for associations between active smoking and breast cancer risk regardless of duration or intensity of exposure. Observed associations were not more pronounced after limiting the referent group to women who were also non-ETS exposed. However, the point estimates reported here are similar in magnitude to a recent meta-analysis (8) although our confidence intervals included the null value. Similarly, we found little to no association with adult ETS. The Surgeon General's report found a summary RR=1.04 (95\% CI 0.99-1.09) for adult ETS exposure (7).

A remaining concern in studies of smoking and breast cancer risk is the potential for residual confounding by alcohol intake (40). Alcohol is consistently associated with breast cancer incidence and is correlated with cigarette smoking status (40). This possibility of residual confounding is exacerbated by the fact that most studies do not have information on lifetime alcohol intake. In this study population, we observed modest positive associations with active smoking prior to adjustment for lifetime alcohol intake. After adjustment, estimates were attenuated towards the null. We also considered that alcohol intake may be a potential effect measure modifier of this relationship. However, no statistically significant interaction was observed which is consistent with two prior cohort studies $(41,42)$ although other studies have noted an elevated risk for cigarette smoking in non-drinkers $(11,13,14)$.

This study has limitations. We were unable to specifically consider spousal ETS exposure, which may lead to higher and more direct exposure. We also did not have information to evaluate intensity of ETS exposure. Although the cohort is large, the number of current smokers was small and at this point of time in follow-up we could consider ER hormone receptor status, but not other potentially relevant tumor subtypes. Similarly, we had limited 
power to consider interactions. Women in this study population, by enrollment criteria, have a family history of breast cancer. Thus, we cannot rule out that possibility that this study population may not be generalizable to all women particularly those without a family history. However, to address this we also carried out analyses stratified by degree of family history and found little evidence of variation by degree of family history (data not shown). Strengths of this study include its prospective study design with detailed exposure assessment that permitted us to evaluate multiple windows of biologic susceptibility. We were able to jointly consider the impact of active smoking and ETS. Additionally, the evaluation of alcohol consumption across the life course was an important strength of this study and permitted a more sophisticated adjustment of confounding by alcohol.

The findings in this prospective cohort support modest associations between tobacco smoke and breast cancer risk for both childhood and in utero ETS exposure.

\section{Supplementary Material}

Refer to Web version on PubMed Central for supplementary material.

\section{Acknowledgments}

The authors recognize the helpful feedback from Drs. Lauren Wilson and Katie O'Brien.

Sources of financial support: This research was supported in part by the Intramural Research Program of the NIH, National Institute of Environmental Health Sciences (Z01-ES044005)

\section{References}

1. Smith CJ, Perfetti TA, Rumple MA, Rodgman A, Doolittle DJ. "IARC group 2A Carcinogens" reported in cigarette mainstream smoke. Food Chem Toxicol. 2000; 38:371-83. [PubMed: 10722891]

2. Terry PD, Rohan TE. Cigarette smoking and the risk of breast cancer in women: A review of the literature. Cancer Epidemiology Biomarkers \& Prevention. 2002; 11

3. Hecht SS. Tobacco smoke carcinogens and breast cancer. Environ Mol Mutagen. 2002; 39:119-26. [PubMed: 11921179]

4. Li DH, Wang MY, Dhingra K, Hittelman WN. Aromatic DNA adducts in adjacent tissues of breast cancer patients: Clues to breast cancer etiology. Cancer Res. 1996; 56:287-93. [PubMed: 8542582]

5. Perera FP, Estabook A, Hewer A, et al. Carcinogen-DNA Adducts in Human Breast-Tissue. Cancer Epidemiology Biomarkers \& Prevention. 1995; 4:233-8.

6. Conway K, Edmiston SN, Cui L, et al. Prevalence and spectrum of p53 mutations associated with smoking in breast cancer. Cancer Res. 2002; 62:1987-95. [PubMed: 11929815]

7. U.S. Department of Health and Human Services. The Health Consequences of Smoking: 50 Years of Progress. A Report of the Surgeon General. U.S. Department of Health and Human Services, Centers for Disease Control and Prevention, National Center for Chronic Disease Prevention and Health Promotion, Office on Smoking and Health; Atlanta, GA: 2014. Printed with corrections, January 2014

8. Gaudet MM, Gapstur SM, Sun J, Diver WR, Hannan LM, Thun MJ. Active smoking and breast cancer risk: original cohort data and meta-analysis. Journal of the National Cancer Institute. 2013; 105:515-25. [PubMed: 23449445]

9. Bjerkaas E, Parajuli R, Weiderpass E, et al. Smoking duration before first childbirth: an emerging risk factor for breast cancer? Results from 302,865 Norwegian women. Cancer Causes Control. 2013; 24:1347-56. [PubMed: 23633026] 
10. Rosenberg L, Boggs DA, Bethea TN, Wise LA, Adams-Campbell LL, Palmer JR. A prospective study of smoking and breast cancer risk among African-American women. Cancer Causes Control. 2013; 24:2207-15. [PubMed: 24085586]

11. Dossus L, Boutron-Ruault MC, Kaaks R, et al. Active and passive cigarette smoking and breast cancer risk: results from the EPIC cohort. Int J Cancer. 2014; 134:1871-88. [PubMed: 24590452]

12. Nyante SJ, Gierach GL, Dallal CM, et al. Cigarette smoking and postmenopausal breast cancer risk in a prospective cohort. Br J Cancer. 2014; 110:2339-47. [PubMed: 24642621]

13. Gram IT, Little MA, Lund E, Braaten T. The fraction of breast cancer attributable to smoking: The Norwegian women and cancer study 1991-2012. Br J Cancer. 2016; 9:154.

14. Gram IT, Park SY, Kolonel LN, et al. Smoking and Risk of Breast Cancer in a Racially/Ethnically Diverse Population of Mainly Women Who Do Not Drink Alcohol: The MEC Study. American journal of epidemiology. 2015; 182:917-25. [PubMed: 26493265]

15. Catsburg C, Miller AB, Rohan TE. Active cigarette smoking and risk of breast cancer. Int J Cancer. 2015; 136:2204-9. [PubMed: 25307527]

16. Hiatt RA, Haslam SZ, Osuch J. The breast cancer and the environment research centers: transdisciplinary research on the role of the environment in breast cancer etiology. Environmental health perspectives. 2009; 117:1814-22. [PubMed: 20049199]

17. Colditz GA, Frazier AL. Models of breast cancer show that risk is set by events of early life: prevention efforts must shift focus. Cancer Epidemiol Biomarkers Prev. 1995; 4:567-71. [PubMed: 7549816]

18. DeRoo LA, Cummings P, Mueller BA. Smoking before the first pregnancy and the risk of breast cancer: a meta-analysis. American journal of epidemiology. 2011; 174:390-402. [PubMed: 21719745]

19. Nichols HB, Baird DD, DeRoo LA, Kissling GE, Sandler DP. Tubal ligation in relation to menopausal symptoms and breast cancer risk. Br J Cancer. 2013; 109:1291-5. [PubMed: 23922107]

20. National Institute of Environmental Health Sciences. Outcome Validation

21. Greenland S, Pearl J, Robins JM. Causal diagrams for epidemiologic research. Epidemiology. 1999:37-48. [PubMed: 9888278]

22. Xu X, Dailey AB, Peoples-Sheps M, Talbott EO, Li N, Roth J. Birth weight as a risk factor for breast cancer: a meta-analysis of 18 epidemiological studies. J Womens Health. 2009; 18:1169-78.

23. Hilakivi-Clarke L. Maternal exposure to diethylstilbestrol during pregnancy and increased breast cancer risk in daughters. Breast Cancer Res. 2014; 16:208. [PubMed: 25032259]

24. Bernstein L, Pike MC, Lobo RA, Depue RH, Ross RK, Henderson BE. Cigarette smoking in pregnancy results in marked decrease in maternal hCG and oestradiol levels. Br J Obstet Gynaecol. 1989; 96:92-6. [PubMed: 2923845]

25. Tomatis L. Overview of perinatal and multigeneration carcinogenesis. IARC Sci Publ. 1989; 96:115.

26. Sandler DP, Everson RB, Wilcox AJ. Passive smoking in adulthood and cancer risk. American journal of epidemiology. 1985; 121:37-48. [PubMed: 3964991]

27. Sanderson M, Williams MA, Malone KE, et al. Perinatal factors and risk of breast cancer. Epidemiology. 1996:34-7. [PubMed: 8664398]

28. Sanderson M, Williams M, Daling J, et al. Maternal factors and breast cancer risk among young women. Paediatric and perinatal epidemiology. 1998; 12:397-407. [PubMed: 9805713]

29. Weiss HA, Potischman NA, Brinton LA, et al. Prenatal and perinatal risk factors for breast cancer in young women. Epidemiology. 1997:181-7. [PubMed: 9229211]

30. Hodgson ME, Newman B, Millikan RC. Birthweight, parental age, birth order and breast cancer risk in African-American and white women: a population-based case-control study. Breast Cancer Res. 2004; 6:R656-R67. [PubMed: 15535848]

31. Park SK, Garcia-Closas M, Lissowska J, et al. Intrauterine environment and breast cancer risk in a population-based case-control study in Poland. International journal of cancer. 2006; 119:2136-41. [PubMed: 16804898] 
32. Park SK, Kang D, McGlynn KA, et al. Intrauterine environments and breast cancer risk: metaanalysis and systematic review. Breast Cancer Res. 2008; 10:R8. [PubMed: 18205956]

33. Strohsnitter WC, Noller KL, Titus-Ernstoff L, et al. Breast cancer incidence in women prenatally exposed to maternal cigarette smoke. Epidemiology. 2005; 16:342-5. [PubMed: 15824550]

34. Sanderson M, Daling JR, Doody DR, Malone KE. Perinatal factors and mortality from breast cancer. Cancer Epidemiol Biomarkers Prev. 2006; 15:1984-7. [PubMed: 17035409]

35. Lin Y, Kikuchi S, Tamakoshi K, et al. Active smoking, passive smoking, and breast cancer risk: findings from the Japan Collaborative Cohort Study for Evaluation of Cancer Risk. J Epidemiol. 2008; 18:77-83. [PubMed: 18403857]

36. Luo J, Margolis KL, Wactawski-Wende J, et al. Association of active and passive smoking with risk of breast cancer among postmenopausal women: a prospective cohort study. Bmj. 2011; 1

37. Xue F, Willett WC, Rosner BA, Hankinson SE, Michels KB. Cigarette smoking and the incidence of breast cancer. Arch Intern Med. 2011; 171:125-33. [PubMed: 21263102]

38. Reynolds P, Goldberg D, Hurley S, et al. Passive smoking and risk of breast cancer in the California teachers study. Cancer Epidemiol Biomarkers Prev. 2009; 18:3389-98. [PubMed: 19959687]

39. Russo J, Tay LK, Russo IH. Differentiation of the mammary gland and susceptibility to carcinogenesis. Breast cancer research and treatment. 1982; 2:5-73. [PubMed: 6216933]

40. Hamajima N, Hirose K, Tajima K, et al. Alcohol, tobacco and breast cancer-collaborative reanalysis of individual data from 53 epidemiological studies, including 58,515 women with breast cancer and 95,067 women without the disease. Br J Cancer. 2002; 87:1234-45. [PubMed: 12439712]

41. Cui Y, Miller AB, Rohan TE. Cigarette smoking and breast cancer risk: update of a prospective cohort study. Breast cancer research and treatment. 2006; 100:293-9. [PubMed: 16773435]

42. Gram IT, Braaten T, Terry PD, et al. Breast cancer risk among women who start smoking as teenagers. Cancer Epidemiol Biomarkers Prev. 2005; 14:61-6. [PubMed: 15668477] 


\section{Pack-years of Cigarette Smoking}
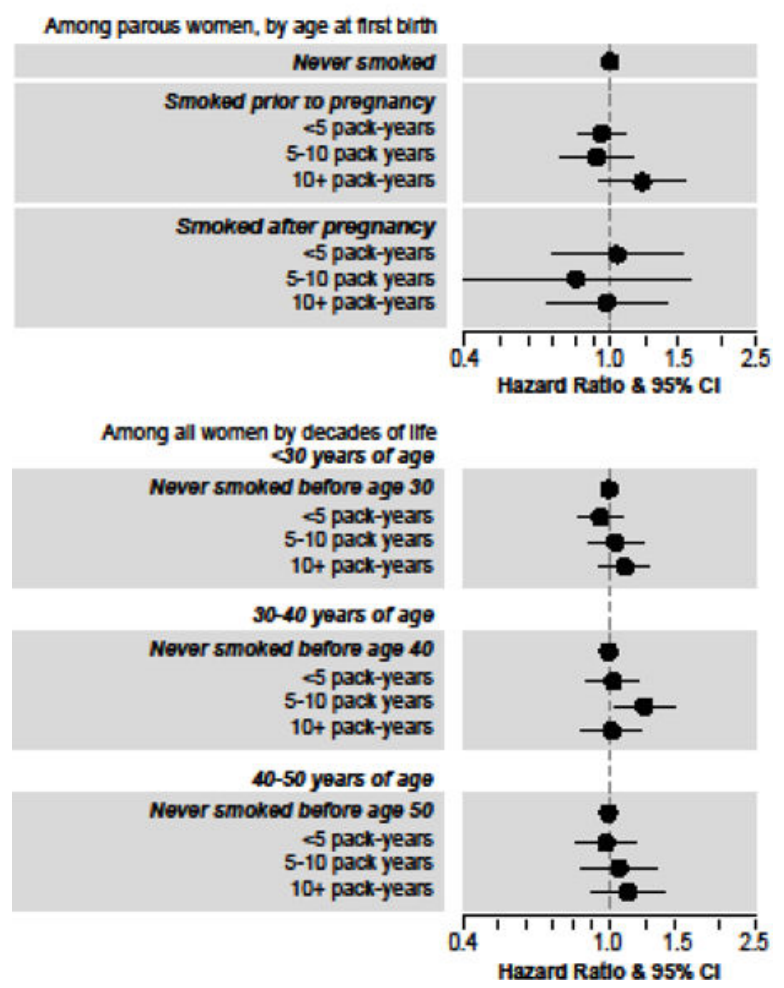

Fig 1.

Invasive breast cancer risk in association with pack-years of cigarette smoking among parous women by age at first birth and in all women by decades of life, NIEHS Sister Study. 


\section{Household Smoking During Pregnancy}

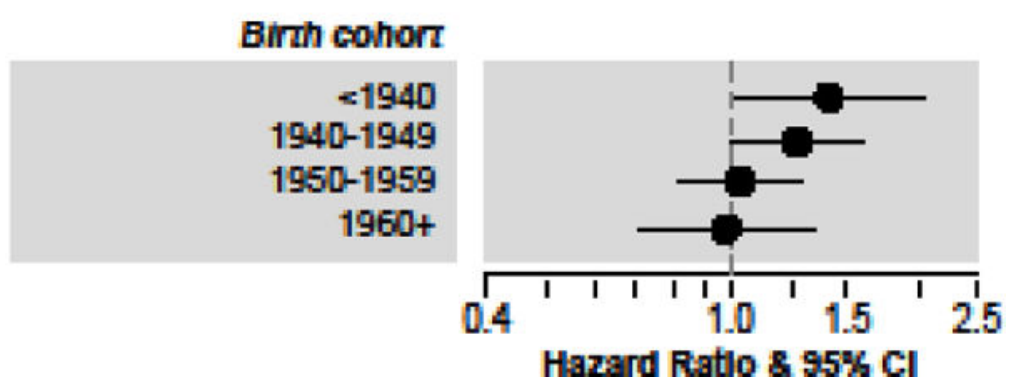

Fig 2.

Household smoking during mother's pregnancy and invasive breast cancer risk in never smokers, NIEHS Sister Study. 


\section{롤}
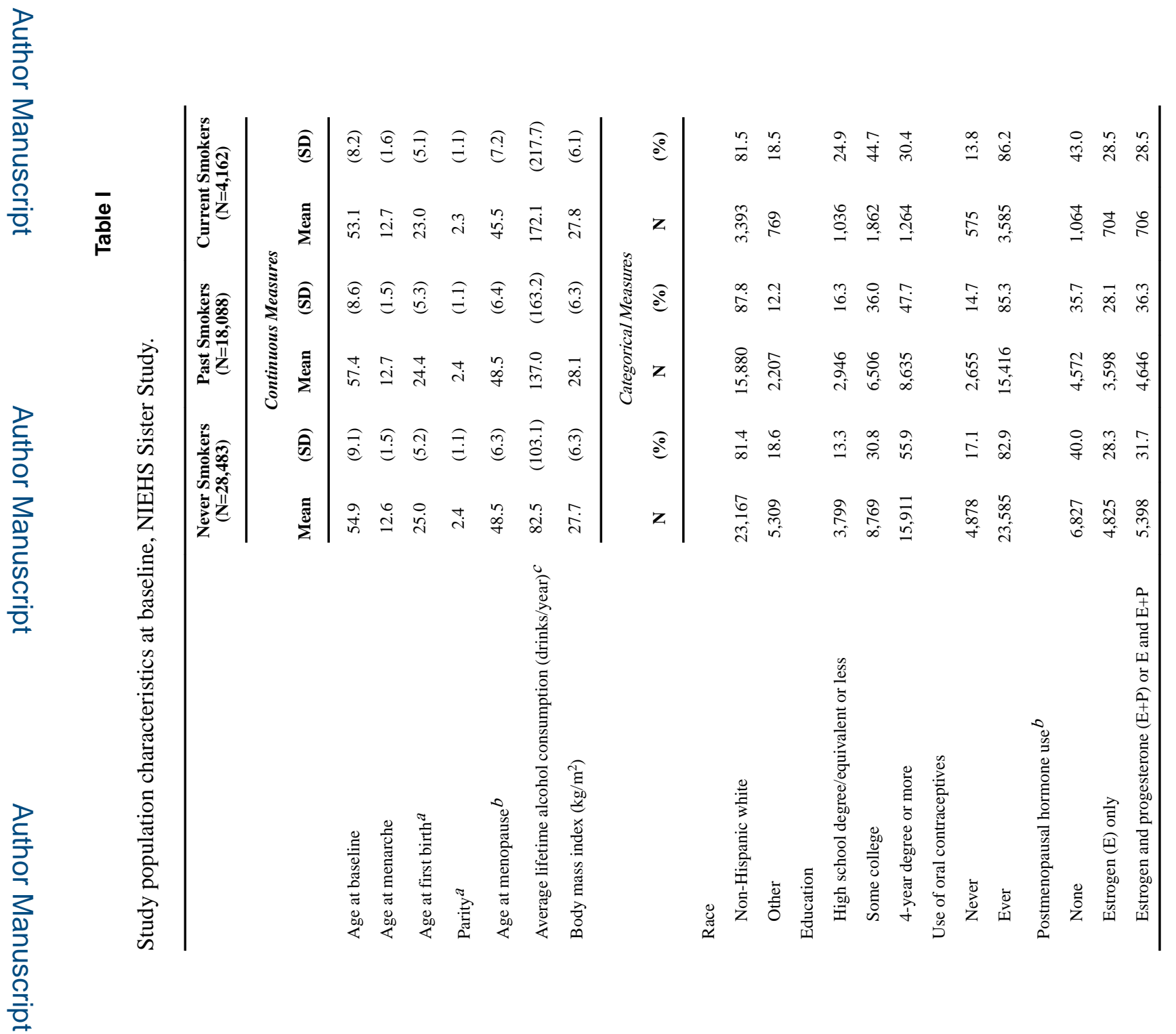

Cancer Causes Control. Author manuscript; available in PMC 2018 July 01. 

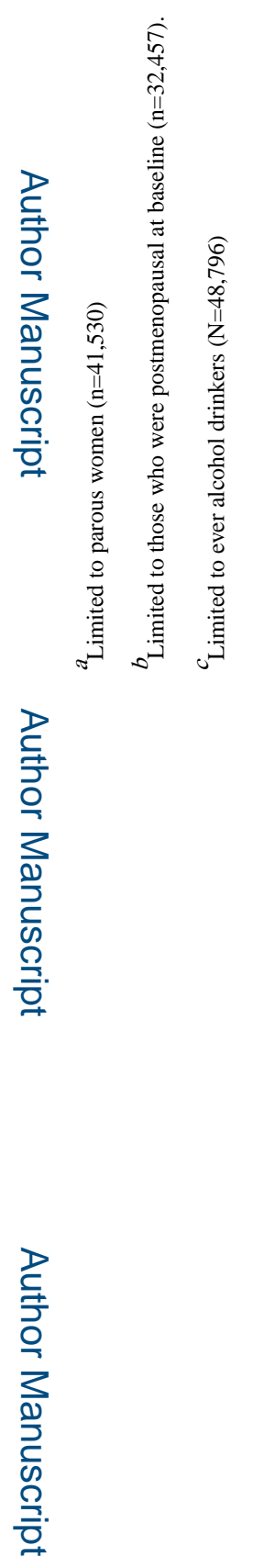

롤

Cancer Causes Control. Author manuscript; available in PMC 2018 July 01. 


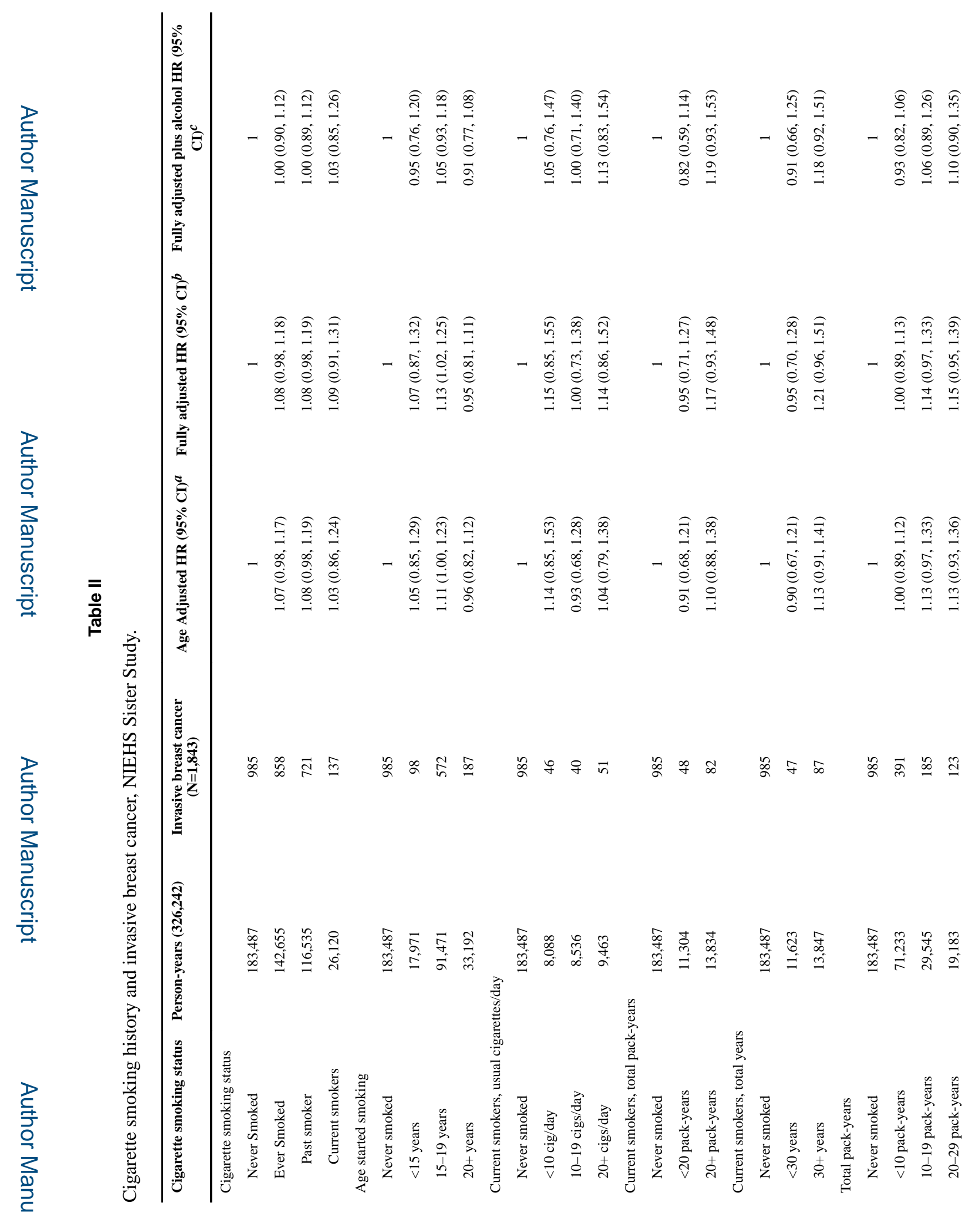

Cancer Causes Control. Author manuscript; available in PMC 2018 July 01. 
White et al.

Page 16

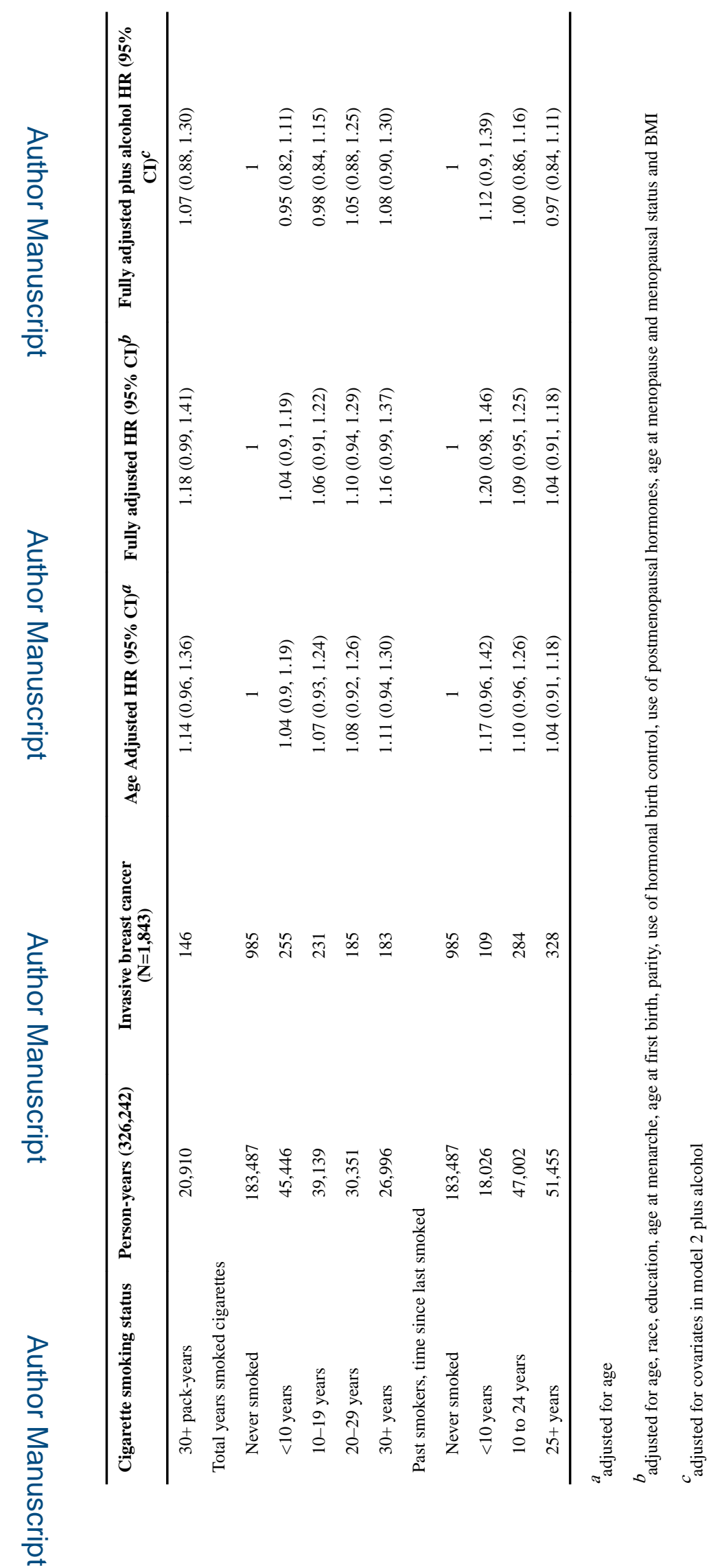

Cancer Causes Control. Author manuscript; available in PMC 2018 July 01. 
Table III

Environmental tobacco smoke (ETS) exposure in never smokers, NIEHS Sister Study

\begin{tabular}{|c|c|c|c|c|}
\hline $\begin{array}{l}\text { Environmental Tobacco Smoke } \\
\text { (ETS) in never smokers }\end{array}$ & Person-years $(183,487)$ & $\begin{array}{l}\text { Invasive breast } \\
\text { cancer }(\mathrm{N}=985)\end{array}$ & $\begin{array}{l}\text { Age Adjusted HR (95\% } \\
\text { CI) }\end{array}$ & $\begin{array}{l}\text { Fully adjusted HR } \\
(\mathbf{9 5 \%} \mathrm{CI})\end{array}$ \\
\hline \multicolumn{5}{|l|}{ Ever $\operatorname{ETS}^{b}$} \\
\hline None & 36,047 & 177 & 1 & 1 \\
\hline Yes & 143,982 & 791 & $1.06(0.90,1.25)$ & $0.98(0.81,1.18)$ \\
\hline \multicolumn{5}{|l|}{ Total years of ETS $b$} \\
\hline None & 36,047 & 177 & 1 & 1 \\
\hline 0 to 9 & 25,741 & 125 & $0.99(0.79,1.25)$ & $0.94(0.73,1.22)$ \\
\hline 10 to 19 & 56,864 & 313 & $1.11(0.92,1.33)$ & $1.03(0.84,1.27)$ \\
\hline 20 to 29 & 30,030 & 172 & $1.11(0.89,1.37)$ & $0.95(0.75,1.22)$ \\
\hline $30+$ & 31,347 & 181 & $1.01(0.81,1.25)$ & $0.93(0.73,1.20)$ \\
\hline \multicolumn{5}{|l|}{ Adult ETS $b$} \\
\hline No & 85,383 & 462 & 1 & 1 \\
\hline Yes & 97,074 & 517 & $0.89(0.79,1.02)$ & $0.86(0.74,1.00)$ \\
\hline \multicolumn{5}{|l|}{ Years of adult ETS $b$} \\
\hline None & 85,383 & 462 & 1 & 1 \\
\hline 0 to 9 & 45,381 & 227 & $0.90(0.77,1.06)$ & $0.86(0.72,1.03)$ \\
\hline 10 to 19 & 22,706 & 137 & $1.00(0.83,1.22)$ & $0.95(0.76,1.19)$ \\
\hline $20+$ & 28,986 & 153 & $0.80(0.66,0.97)$ & $0.77(0.62,0.97)$ \\
\hline \multicolumn{5}{|l|}{ Childhood ETS ${ }^{c}$} \\
\hline No & 63,042 & 314 & 1 & 1 \\
\hline Yes & 117,909 & 658 & $1.12(0.98,1.29)$ & $1.12(0.98,1.29)$ \\
\hline \multicolumn{5}{|l|}{ Years of childhood ETS ${ }^{c}$} \\
\hline None & 63,042 & 314 & 1 & 1 \\
\hline$<10$ & 20,465 & 98 & $0.99(0.79,1.24)$ & $1.00(0.79,1.25)$ \\
\hline 10 to 14 & 17,477 & 95 & $1.13(0.89,1.42)$ & $1.10(0.87,1.40)$ \\
\hline 15 to 17 & 15,034 & 84 & $1.13(0.88,1.43)$ & $1.12(0.88,1.43)$ \\
\hline 18 & 64,933 & 381 & $1.17(1.00,1.35)$ & $1.17(1.00,1.36)$ \\
\hline \multicolumn{5}{|l|}{ Maternal smoking during pregnancy $c$} \\
\hline Definitely no/Probably no & 125,496 & 669 & 1 & 1 \\
\hline Definitely yes/Probably yes & 47,972 & 258 & $1.07(0.92,1.23)$ & $1.06(0.92,1.23)$ \\
\hline \multicolumn{5}{|c|}{ Paternal smoking 3 months prior to pregnancy ${ }^{c}$} \\
\hline Definitely no/Probably no & 64,758 & 324 & 1 & 1 \\
\hline Definitely yes/Probably yes & 104,923 & 586 & $1.11(0.97,1.27)$ & $1.11(0.97,1.28)$ \\
\hline \multicolumn{5}{|c|}{ Household smoking during pregnancy ${ }^{c}$} \\
\hline Definitely no/Probably no & 76,849 & 383 & 1 & 1 \\
\hline Definitely yes/Probably yes & 92,153 & 530 & $1.15(1.00,1.31)$ & $1.16(1.01,1.32)$ \\
\hline
\end{tabular}


${ }^{b}$ Adult level fully-adjusted models adjusted for age, race, education, age at menarche, age at first birth, parity, use of hormonal birth control, alcohol intake, use of postmenopausal hormones, age at menopause and menopausal status and BMI

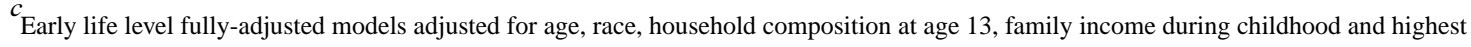
education in household at age 13 